\title{
O PROCESSO DE MATERIALIZAÇÃO DA ÉTICA NA HUMANIDADE, NA PERSPECTIVA DE ENRIQUE DUSSEL
}

\author{
THE PROCESS OF THE MATERIALIZATION OF ETHICS IN \\ HUMANITY IN THE PERSPECTIVE OF ENRIQUE DUSSEL
}

\begin{abstract}
SALAZAR, Gabriel Herrera. Vida Humana, Muerte y Sobrevivencia. Lá Ética Material em la obra de Enrique Dussel.1. ed. Chiapas - México; Centro de Estudios Superiores de México y Centroamérica; 2015.
\end{abstract}

José Moises Nunes da Silva ${ }^{1}$ Regina Celly Clemente Silva ${ }^{2}$ João Paulo da Costa Soares ${ }^{3}$

\begin{abstract}
RESUMO
O presente texto trata-se da resenha do livro Vida Humana, Muerte y Sobrevivencia. Lá Ética Material em la obra de Enrique Dussel.A obra demostra o processo de construção e desenvolvimento de uma filosofia com bases nas teorias latinas, tendo como principal discussão a ética, mediante as mudanças do mundo globalizado e em processo de globalização.
\end{abstract}

Palavras-chaves: humanidade; ética; libertação.

\begin{abstract}
The present text is the review of a book Human Life, Death and Survival. There Material Ethics in the work of Enrique Dussel. The work demonstrates the process of building and developing a philosophy based on Latin theories, having as main discussion ethics, through the changes of the globalized world and in the process of globalization.
\end{abstract}

Keywords: humanity; ethic; release.

\footnotetext{
${ }^{1}$ Doutor em Educação. Professor do Programa de Pós-Graduação em Educação Profissional - PPGEP-IFRN. Licenciado em Matemática pela Universidade Federal do Amazonas. e-mail: ginahillary@hotmail.com

2 Mestranda do Programa de Pós-Graduação em Educação Profissional - PPGEP-IFRN. Licenciada em Pedagogia pela Universidade Federal de Pernambuco UFPE-CAA. e-mail: reginacaruaru@hotmail.com

${ }^{3}$ Mestrando em Educação Profissional - PPGEP-IFRN. Graduado em Gestão de Cooperativas - UFRN. Técnico em Agroindústria - UFRN-EAJ. e-mail: joaopaulomatas@gmail.com
} 
O livro: Vida Humana, Muerte y Sobrevivencia. Lá Ética Material em la obra de Enrique Dussel, Salazar (2015), trata sobre Ética vinculada à Filosofia da Libertação ${ }^{4}$, uma corrente filosófica importante e emergente que se desenvolveu inicialmente na América Latina, com forte movimento na Argentina, país de origem de Enrique Dussel, principal expoente desta corrente. O autor do livro Gabriel Herrera Salazar faz conexões e distinções a respeito da ética em Aristóteles e em Kant, sobre os quais afirma que são contributos para entendermos a perspectiva ética em Dussel.

O livro está estruturado em três seções, a primeira intitulada Principio Material de La ética, numa livre tradução significa: o princípio material da ética; a segunda La concepción de la vida, que significa: A concepção da vida. E a última seção têm sob título Negación material de la vida humana, muerte de la víctima; Punto de partida radical de la ética de la liberación. Que podemos traduzir da seguinte forma: Negação material da vida humana, morte da vítima; Ponto de partida radical da ética da libertação.

Na primeira parte do livro o autor subdivide nos seguintes tópicos: La ética formal aristotélica, La ética formal kantiana e La propuesta ética material de Enrique Dussel, nos quais ele aborda a ética nas perspectivas teóricas de Aristóteles e Kant, que são expoentes e principais referências sobre o tema e a materialização desta ética no cotidiano baseado na análise teórica de Enrique Dussel.

Na segunda seção o autor traz os seguintes tópicos: La evolución creadora de la vida en la filosofia de Henri Bergson; El principio de responsabilidad de Hans Jonas e La vida negada en Enrique Dussel. Aqui ele faz um panorama entre a essência humana e a negação dessa humanidade, por si mesmo e pelos outros, de maneira que passamos a desconstruir nossa humanidade quando não mais percebemos o outro.

Na última parte do livro o autor subdivide a seção nos seguintes tópicos: De la ética de la liberación a la politica de la liberación; El principio crítico-democrático; La política

\footnotetext{
${ }^{4}$ A Filosofia da Libertação é recente se considera uma reflexão filosófica sobre a realidade concreta, em que vivem as pessoas submetidas a diversas formas de dominação, bem como sobre os processos voltados à transformação dessa situação. Trata-se de compreender a realidade da dominação e o processo de libertação. Mance (1996).
} 
subsumida en la ética; La vida humana, la muerte y la sobrevivência. Neste segmento o autor, dentre outras abordagens, faz menção a critica feita pela ética da libertação às estruturas dominantes dos sistemas hegemônicos, os quais produzem efeitos negativos na sociedade, tanto numa perspectiva macro, como numa perspectiva micro. Questões como os sistemas culturais, econômicos e ambientais de algumas sociedades são prejudicados por causa de ações provenientes dessas sociedades que apenas buscam a manutenção de suas estruturas sem preocupar-se com as questões particulares de cada setor da sociedade.

Em Aristóteles o autor delineia a característica fundamental da ética que é harmonia entre a paixão e a razão, virtude e felicidade, salientando que esta tem sua centralidade na ação.

Sobre a ética kantiana o autor afirma que se trata de um auto determinar-se, sem que isso interfira na liberdade do outro, "a razão manda como se deve agir" (p.25), devendo o ser humano utilizar-se da razão como instrumento e guia do seu viver.

Em Dussel, para o autor, a ética é uma ética de valores, fundamentada na vida, materializando-se em três momentos: produção, reprodução e desenvolvimento da vida humana. A obra de Enrique Dussel, ou melhor dizendo, a ética material em sua obra, segundo Salazar, fundamenta-se também na criticidade. Nesta a relatividade ganha seu espaço, pois a verdade de um pode não ser a verdade de outro. Dussel, na visão do autor, desenvolve a sua reflexão sobre a problemática concreta da realidade dos povos latinos, não sendo apenas uma preocupação tão somente teórica, mas um dos aspectos centrais de seu pensamento que é a libertação. Tal libertação está ligada ao pensamento, uma verdadeira forma livre de se pensar, principalmente, com relação aos povos latinos, que ainda são submissos ao continente europeu, não apenas no pensamento, mas também na forma de viver.

Essa reflexão tem pautado o modo latino de pensar e de viver. Na perspectiva de Dussel, conforme Salazar, o latino poderá se libertar tendo como ponto de referência a tomada de consciência de um olhar crítico sobre sua realidade de vida. Tal ênfase pode parecer um tanto contraditória neste livro, visto que, inicialmente o autor usa de teóricos europeus para fazer-nos pensar sobre a ética. Entretanto, uma leitura atenta mostra que o autor ao interpretar 


\section{Revista (O) \\ Debates Insubmissos}

Dussel, observa em seu método, a construção histórica do que seja ética para nos fazer entender que a filosofia pensada por Kant e Aristóteles, se materializam em ações nos seus respectivos contextos históricos e sociais e modelos de sociedade.

Na Filosofia temos o Pássaro de Minerva ${ }^{5}$, aquele que alça voos ao cair da tarde, na cidade, justamente para situar seu contexto e perceber a realidade; a própria gênese da ética da libertação remonta à vida de Dussel. O autor explica tal mecanismo da seguinte maneira: quem age de maneira ética é aquele que luta para libertar a vítima, ou seja, o que tem fome, o que não possui certos privilégios, enfim, os marginalizados. As pessoas éticas devem construir junto aos marginalizados para com eles criar formas novas de pensar a própria existência, como ele cita em sua obra, Ética da Libertação, na Idade da Globalização e da Exclusão: A ação ética, então, tem como imperativo a produção, a reprodução e o desenvolvimento da vida humana em comunidade, (2000) portanto, existe uma obrigação ética de transformar a realidade.

A Filosofia por si, nos mostra como a vida está dada, nos ajuda a refletir sobre ela e não tem o intuito de dizer como a realidade deve ser, caso contrário transformar-se-ia num pensamento ideológico. Todavia, no livro a interpretação perpassa pela Filosofia da Libertação que vai além das ideologias, por isso, a necessidade de utilizar autores europeus para criar essa saída para o pensamento latino. Em outras palavras, devemos refletir sobre nossa realidade e a partir disso criar nosso próprio sistema, nosso próprio modo de pensar, por meio de um voo reflexivo sob nossa realidade. O que nos remete a um livro de Boaventura de Sousa Santos, no qual faz uma abordagem sobre o pensamento europeu dominante e os paradigmas que permeiam o mundo do conhecimento no livro Um discurso sobre as Ciências $(2008)^{6}$.

\footnotetext{
${ }^{5}$ Minerva é o nome romano de Atena, a deusa da sabedoria. A coruja, por sua vez é pássaro ligado à figura de Atena. Contudo, esta alegoria, sobre o pássaro da deusa minerva, foi consagrada por meio da frase de Hegel: "A coruja de Minerva alça seu voo somente com o início do crepúsculo". HEGEL. Wilhelm Friedrich, In: Princípios da Filosofia do Direito. Citado por Ubaldo Nicola. Antologia Ilustrada de Filosofia. Editora Globo, 2005.

${ }^{6}$ Santos, Boaventura de Sousa Um discurso sobre as ciências / Boaventura de Sousa Santos. - 5. ed. - São Paulo, Cortez, 2008.
} 


\section{Revista \\ Debates Insubmissos}

Tanto a sua Filosofia quanto a Ética da Libertação apresentada no livro de Salazar possuem clara opção política pelas vítimas do sistema-mundo, compreendido como o processo de ampliação da influência cultural de um sistema inter-regional (alta cultura ou sistema civilizatório) imposto a outras culturas Dussel (2000). Isso é o que remete à "nossa" Teologia da Libertação ${ }^{7}$, na qual se tem a opção preferencial pelos pobres, claro que voltada para um viés mais político-religioso e vice-versa, porém com princípios parecidos, lembrando-nos ainda dos escritos de Paulo Freire (1987) sobre a Pedagogia do Oprimido. Nesta, há um claro investimento na compreensão de que se faz necessária além da libertação do oprimido, a liberdade do opressor que também deve ser buscada em um processo de conscientização conjunta.

Nessa perspectiva, para Dussel (2000), conforme Salazar, libertar significa também desenvolver a vida humana. A libertação pode ser ética, política, teórica, enfim, ela precisa estar ligada à prática para que tenhamos outro mundo possível, como o próprio autor enfatiza. Para, além disso, se faz necessária a fim de que possamos perceber a nossa humanidade e a humanidade do outro enquanto seres de relação que somos e autores de nossas práticas no mundo.

O livro é de extrema importância para nos aproximarmos das temáticas que ele aborda, de forma crítica e prática, sendo uma leitura dinâmica mesmo aos que não têm proximidade com a língua no qual foi escrito, isso não se torna impedimento para a compreensão do texto.

O texto pode ser de interesse de qualquer estudante e principalmente os ligados às ciências humanas, pois ajuda a sintetizar perspectivas teóricas de áreas ligadas às humanidades, mas não se restringe tão somente ao grupo acadêmico, de uma determinada

\footnotetext{
${ }^{7} \mathrm{~A}$ Teologia da Libertação não caiu do céu nem foi inventada por algum teólogo inspirado. Mas emergiu do bojo desse movimento maior mundial e latino-americano, por um lado político e por outro eclesial. Ela se propôs pensar as práticas eclesiais e políticas em curso à luz da Palavra da Revelação. Ela comparecia como palavra segunda, crítica e regrada, que remetia à palavra primeira que é a prática real junto e com os oprimidos. Alguns nomes seminais merecem ser aqui destacados que, por primeiro, captaram a relevância do momento histórico e souberam encontrar-lhe a fórmula adequada, Teologia da Libertação: Gustavo Gutiérrez do Peru, Juan Luiz Segundo do Uruguai, Hugo Asmann do Brasil e Enrique Dussel e Miguez Bonino, ambos da Argentina. Esta foi a primeira geração. Quarenta anos da Teologia da Libertação

(BOFF, 2011).
} 
área. Qualquer pessoa interessada na temática pode se enveredar pela leitura de Enrique Dussel, desta obra e de tantas outras, pois seus textos são contemporâneos e passeiam por teorias que são instrumentos para a vida nesse processo de globalização por qual passa o mundo. É um livro que ajuda a pensar sobre o modo de se portar eticamente numa sociedade, a leitura, por sua vez não tem o intuito de ser um tratado sobre a ética, mas sim, dentre outros aspectos, de fazer com que nos questionemos sobre de que modo estamos lidando com a nossa humanidade, de como estamos cuidando e lidando com a nossa vida e com a vida do outro. Tal reflexão de faz necessária visto, que podemos compreender para intervir e transformar as realidades de exclusão existentes.

\section{REFERÊNCIAS}

DUSSEL, Enrique. Ética da Libertação na idade da globalização e da exclusão. Petrópolis: Vozes, 2000.

MANCE, Euclides André. Desafios que a Filosofia da Libertação Enfrenta. Cadernos da FAFIMC. Viamão, N.15, janeiro/junho de 1996, p.95-142.

FREIRE, Paulo. Pedagogia do Oprimido, 17 ed. Rio de Janeiro, Paz e Terra, 1987.

Submetido em: $28 / 05 / 2019$

Aprovado em: 25/07/2019 